\section{Apply for a Program}

The AATS Foundation provides a number of educational and research opportunities to cardiothoracic surgeons around the world each year. The following programs will be accepting applications through December 1, 2020.*

\section{ADULT CARDIAC}

James L. Cox Fellowship in Atrial Fibrillation Surgery-Sponsored by AtriCure Inc.

Affords newly graduated cardiothoracic surgeons the opportunity to improve their atrial fibrillation techniques at a host institution.

\section{THORACIC}

Thoracic Surgical Robotics Fellowship-Sponsored by Intuitive Surgical

Familiarizes North American general thoracic fellows and their attending surgeons with the da Vinci robotics system during advanced training. Awardees who complete the fellowship are eligible to participate in the Advanced Lobectomy Course.

\section{Thoracic Surgery Training Fellowship-Sponsored by Ethicon China}

Offers young surgeons from China the opportunity to obtain advanced thoracic surgery skills at North American institutions.

\section{MULTI-SPECIALTY}

\section{AATS Foundation Cohn Lectureship}

Provides a unique opportunity to bring an AATS member lecturer to a North American institution.

Japanese Association for Thoracic Surgery Fellowship-Sponsored by Medtronic

Engages Japanese cardiothoracic surgeons in an interactive educational opportunity to observe and converse with specialists in the treatment of heart valve disease or advanced minimally invasive thoracic surgery at select host institutions in North America.

\section{Summer Intern Scholarship-Supported by Scanlan}

Provides first- and second-year medical students with an eight-week summer internship in an AATS member's cardiothoracic surgery department.

\section{Research Scholarship}

Supports North American surgeons with a two-year grant of $\$ 80,000$ each year to pursue research, training, and clinical experience.

\section{Surgical Investigator Program}

Provides up to $\$ 50,000$ annually to support innovative clinical or translational research by young cardiothoracic surgeons for up to two years.

*Please note that this year's fall award timeline may be impacted by COVID-19.

\section{The Western Thoracic Surgical Association}

\section{Save the Date}

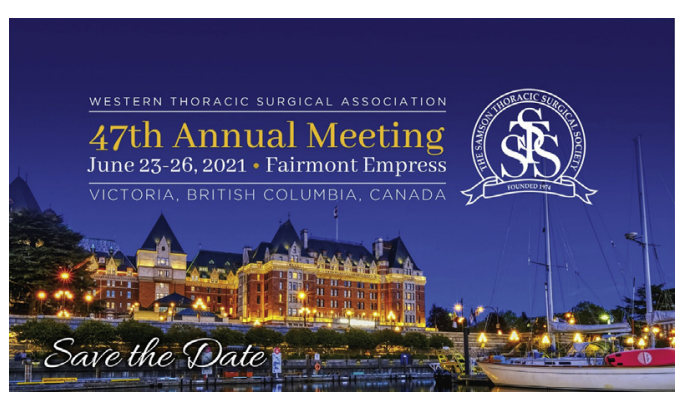

WTSA 47th Annual Meeting

June 23-26, 2021

Fairmont Empress

Victoria, BC, Canada

\section{Applications for WTSA Membership}

The WTSA is now accepting Applications for Membership online for Active as well as Candidate membership status for the 2021 membership cycle. Visit the WTSA Web site at www.westernthoracic.org to read the complete membership eligibility requirements and to initiate an online application.

\section{Active Member}

$\$ 375$ annually, plus $\$ 50$ initiation fee

Applicant must meet all membership criteria, including but not limited to:

- Reside within or have completed a cardiothoracic residency training program within the geographic limits of the Association.

- Have been engaged in the practice of thoracic and cardiovascular surgery for at least three years 